\title{
An Integrated Implementation Framework for an Efficient Transformation to Online Education
}

\author{
Ahmed Al-Hunaiyyan ${ }^{1}$, Salah Al-Sharhan ${ }^{2}$, Rana Alhajri ${ }^{3}$, Andrew Bimba ${ }^{4}$ \\ Computers and Info. Systems Department, Public Authority for Applied Education and Training (PAAET), Kuwait ${ }^{1}$ \\ School of Business and Information Technology, College of North Atlantic- Qatar ${ }^{2}$ \\ Computer Department, Public Authority for Applied Education and Training (PAAET), Kuwait ${ }^{3}$ \\ College of Information Technology, University Malaya- Malaysia ${ }^{4}$
}

\begin{abstract}
The least developed countries have been tasked with introducing effective e-learning frameworks as they look to overcome technology inadequacies and lack of research support or vision. Ongoing efforts are reliant upon a mixed-methods approach. A systematic literature analysis and a quantitative examination have been undertaken to achieve a thorough assessment of the available data taken from educational facilities in Kuwait. Results show clear support for embracing e-learning, with most participants recognizing its positives when faced with the scope of challenges its practice may incorporate. Consequently, the authors recommend a framework that is integrated to support a smooth upgrade to online teaching in a manner that furthers the efficacy and understanding of elearning potential in the context of education in Kuwait and neighboring countries, with a particular focus on how to function during a pandemic lockdown. The proposed framework is structured according to five key tiers: infrastructure, e-learning delivery, LMS, e-Content, and user portal. In support of this, a model of e-Content development is proposed to assist with the establishment and execution of educational materials, in particular, to cope with the lack of digital learning materials in Arabic.
\end{abstract}

Keywords-Distance learning; e-learning framework; COVID19 pandemic; e-learning delivery; $e$-Content

\section{INTRODUCTION}

The worldwide technology boom has resulted in the transfer of education via desktops to learn remotely, meaning the increased potential for fresh and innovative education approaches. Technological progress supports educational facilities having the capacity to adapt to remote teaching. Still, it would be false to claim that all educators have seamlessly achieved this transformation because of a lack of direction or advice on how it should best be achieved. Indeed, despite its advantages, turning to e-learning at a challenging time - such as during the pandemic lockdown - can prove complicated and damaging, involving numerous connected factors that need to be analyzed and adapted to meet robust models and frameworks. Such e-learning frameworks and models need to ensure this new generation of learners are effectively connected, enhancing their ability to learn in isolation and take advantage of new software [1, 2]. Those decision-makers involved in establishing a new learning landscape are focused on organizing educational facilities and cities into exemplars of learning development that is in balance with each other [3]. As more moves are being made to establish Smart Cities that direct job markets and businesses toward knowledge-based contributions, the OECD is calling for educational institutions to focus on more than education alone. Indeed, they call for universities to be aligned with knowledge-concentrated job markets, allowing those who graduate to fit in smoothly with the smart city vision [4].

Innovative frameworks are being launched, as researchers gain a greater awareness of potential when answering the problems and pitfalls of technology upgrades. In the context of this paper, the definition of 'framework' matches that defined by [5]: "standardized set of concepts, practices, and criteria, applicable on a certain type of issue, to provide solving solutions.” Education providers have had little choice to move from teaching in-person to remote solutions due to the pandemic. Therefore, this transformation's speed without a tried and trusted process, advice, or practical execution framework means that the results have not always been positive - particularly among those that remain less developed technologically speaking [6, 7]. The effective rollout of remote and blended learning solutions in less developed countries demands an appreciation of how technology best facilitates both learning and teaching practices that lead to positive outcomes [8].

Most importantly, this transformation requires restructuring each educational facility's dynamics to suit each student's learning capacity and securing a move from traditional teaching influence on digital influence that is just as interactive and impactful as before, if not more so. The potential for making this shift has been fully realized thanks to e-learning versatility, but that does not mean that all education providers worldwide have done so in a robust fashion particularly in less developed nations $[9,10]$. The absence of applicable frameworks for guiding educators in securing this transformation into a new age of education is undoubtedly one of the key factors holding systems back [11, 12, 13, 6, 14].

Kuwait remains a developing nation, meaning that all the benefits of ICTs and e-learning potential were still behind many other countries prior to pandemic lockdown challenges. Most education providers were still focused on traditional methods, therefore, learning via classroom settings [9, 15]. Although there have been numerous moves to facilitate online learning, few have been successful [15, 9]. So, although Kuwait has seen some education providers becoming familiar with online learning potential, as Alkharang [9] confirms, its 
progress has not matched that of other nations due to the need to upgrade current systems and technology. Section 4 of this paper looks further into Kuwait to analyze precisely why elearning adoption has caused certain rifts and dilemmas. The focus is on highlighting key factors to enable identifying a robust framework required for effective integration.

\section{A. Research Objectives}

Several e-learning frameworks have been used to solve unique e-learning problems. Nevertheless, these frameworks mainly cover issues of e-learning systems development, application and adoption while the development of electronic content (e-Content) and its role in the educational process is missing especially digital Arabic learning content [8]. Therefore, the aim of the current study is to develop an integrated framework in the context of virtual and smart classrooms environment to effectively adapt the efficient use of technologies in the Kuwaiti national educational systems and the developing countries in the region. The framework is developed in the light of identified critical factors, international practices, and the outcome of the survey study presented in Section 4. Electronic content utilization, which has been identified as vital to an effective e-learning framework, is assessed here as a singular entity rather than as part of a whole.

The shift to online education requires digitizing the conventional curricula and transferring the curricula into interactive online subjects that ensure an efficient learning process and provide pedagogical strategies to achieve the educational objectives and learning outcomes. The importance of this analysis is the ability to successfully merge the technical and pedagogical aspects of education in a manner that maximizes the utilization of e-Content, that makes the most of teachers' roles regardless of how they are able to interact with students, and that integrates with the latest technological innovations [16]. Furthermore, the framework focuses on effectively addressing the challenges specific to Kuwait and similar neighboring countries, incorporating the issues identified by the pandemic lockdown.

The paper begins with a literature review in Section 2, then moves on to the research methodology in Section 3, the case study in Section 4, and the e-learning framework in Section 5. The final section concludes the research and proposes future directions.

\section{LITERATURE REVIEW}

Developing a robust e-learning system requires a focused examination of the resources and avenues that the education provider has access to. As proposed [17], the design, assessment, and rolling out of new frameworks demand firm insights into the various features and versatilities of online technologies. Plus, this paper explores the technical and pedagogical aspects of teaching remotely, together with eContent utilization to meet key learning goals.

\section{A. E-Learning Delivery}

Various concepts of e-learning and remote education have drawn a wide range of research initiatives. Nevertheless, strong similarities exist to show that all different concepts can be brought under the banner of interactions between students and educators that occur regardless of time and place [18]. Elearning itself can be defined as the utilization of online technology in a manner that allows for learning remotely [19]. However, various online learning setups are available such as standalone or virtual classroom options, the use of simulations, and embedded or blended learning [20, 21, 22]. Despite this, two distinct forms of online learning have been identified. The first is an all-encompassing approach, demanding every aspect to be carried out in an online or virtual form and no teacher or student interactions occurring in person [23]. As perhaps expected, therefore, the second form involves a blended approach, with online technology utilized as much as possible but not necessarily defining every interaction - more of a 'Smart classroom' that facilitates online learning but is still led by recognized traditional methods [22, 24]. Essential for both these approaches is the adoption of Learning Management Systems (LMSs), via which students and educators can communicate.

Moving education online alters learning structure, establishing new and innovative forms of teaching that can be either synchronous or asynchronous. The asynchronous approach requires the educator to provide solutions in realtime, whereas an asynchronous technique does not rely on real-time interaction [25]. The merging of various learning techniques has been trialed in Poland (Ożadowicz, 2020), tackling pandemic lockdown challenges with a combination of synchronous and asynchronous approaches. Such a strategy was adopted to suit the challenges of engineering, being a subject that requires a certain degree of hands-on work on-site and in the laboratory. Hence, students were still able to perform the practical aspects of their work while also learning from teachers online. Research elsewhere [26, 27], however, claims that teaching in person should not be wholly sidelined and remains the most important aspect of any education, despite the flexibility allowed by online potential. These researchers warn against adopting an asynchronous approach for the sake of convenience alone, stressing the more laid back and reflective benefits of teaching in person. Nevertheless, other researchers seek to merge learning approaches to make the best of all avenues, calling for a versatile and hybrid outlook on education [28, 29]. A wide range of digital learning approaches has been trialed since the pandemic began. Nerantzi (2020), for example, promoted peer instruction and flipped learning to education providers in the UK. Such methods focus on simulating knowledge accrual in merged settings, so long as students are engaged in an active sense. The peer instruction approach involves scaffolding, using peer-peer interaction, which promotes active engagement and promotes conceptual understanding outside the classroom. The proposed technique's main aim is to provide instructors with modules to maximize student engagement and learning.

With more and more studies of online learning potential taking place, the various frameworks and practicalities involved are under constant scrutiny. Examples of key priorities for researchers include designing online teaching materials and their sustainability [30, 31, 32]. Additional areas of concern are the preparedness of teachers, the willingness to embrace technology, the form of delivery [14, 28, 29, 33], the 
role of the smart classroom [34], remote learning [35, 1], and mobile learning $[36,37]$. Other researchers look to be more specific by stressing Critical Success Factors (CSFs), defined as institutional management, learning environment, instructional design, service support, and course evaluation [38]. Similarly, having a recognized smart classroom framework is recommended by Al-Sharhan [34] as a way of narrowing down the focus on remote learning. This method involves directing the smart classroom capabilities so that curriculum and ICT features become seamlessly integrated. An approach that coincides with [36] put forward a form of remote learning that blends mobile technology with established pedagogy. This alternative involves utilizing mobile technology within a shared virtual learning zone, enhanced to incorporate e-Content and LMS aspects.

Support for effective remote learning involves a range of obstacles and dilemmas. Some studies have analyzed these issues in-depth, exploring problems related to communication, timekeeping, infrastructure, and user familiarity with advancing technology [39]. A varied scope of research concerning how education can be readjusted can be found around the world. For example, in the Philippines, [7] explored the consequences of cutting out face-to-face interaction completely. This led to identifying issues that included teaching with no particular style, poor standards, and the ability to learn solely from domestic surroundings. In contrast, in South Africa, the consequences of remote learning reliance on students from disadvantaged backgrounds have come under scrutiny [6]. This research was carried out with the motivation to find more flexible learning avenues that allow students from a wide range of social situations to continue to access quality education. The conclusions point to a 'digital divide' as preventing learners from disadvantaged backgrounds from making the most of technology in the same way that others can.

\section{B. e-Content Development}

Many approaches, models and frameworks exist when designing quality online learning environments. These approaches assist and guide instructional designers through the design and development of e-Content. Learning management systems (LMS) provide an instructor a way in which to create and deliver content, monitor learners' participation, and assess learners' performance. In fact, many institutions may have one or two content-authoring tools supported by the LMS. These fundamental tools allow institutions to form e-Content solutions that embrace a range of teaching approaches, as well as directing current environments to suit a range of social scenarios, learning capabilities, and gender differences [40, 41, 42]. Such a method, designed to merge student engagement with a range of teaching styles and methods, was proposed in a 2016 study [32]. The focus for this study was on online developers and designers rather than the educators themselves. While, to a certain degree, the attributes that learners bring to their challenges will come to define what they can achieve, it is also the case that an efficacious course design enhanced by innovative technology will facilitate their potential [32]. As far as e-Content is concerned, six key developmental stages are identified as analysis, design, development, testing, implementation, and evaluation [31]. Furthermore, this study identifies pedagogical concerns in how this new content is driven, incorporating a wide range of influencing factors, such as teaching and learning styles, forms of examination, overall strategies and processes, recognized practice, and the ultimate aims of learning content [31]. The educator remains crucial in all of these contexts, effectively facilitating the impact that digital technologies have on students' learning progress [43, $1]$.

Instructional design (ID) is integral to establishing robust e-Content [44]. For those who practice ID, they require a strategy that is both systematic and repetitive in how problems are addressed. The process involves establishing the instructional objectives, assessing the key goals and learning domains, clarifying the outcomes required, and drawing on relevant test questions to complement the overall strategy. Five examples of developed ID models were placed under analysis by the OECD: gaming, virtual laboratories, collaborative projects, real-time assessments, and skills-based assessments [4]. In contrast, an alternative approach identified four crucial ID dimensions in the form of function, origin, source, and analysis [45]. These defining dimensions were merged to establish ten effective actions that make up a firm methodological ID strategy. Elsewhere, the prioritization of pedagogical objectives despite lockdown complications has led to creating various methods that cut down on time a learner needs (Cahapay, 2020). This approach requires determining the most vital aspects of a curriculum, then relieving teachers from juggling too many aspects as they help students to progress. Both hybrid and fully online learning strategies are possible in this respect. However, less developed countries will likely encounter far more social and cultural issues adjusting to this new outlook.

\section{MethodolOGY}

An analysis has been undertaken to address two categories of research literature looking into how online learning is currently being perceived, including the various strategies and e-learning frameworks proposed for e-learning implementation and the utilization of e-Content. The literature that has been written under the current lockdown situation was favored, but not exclusively. Once carried out, survey research followed to draw in key data thanks to a questionnaire constructed to connect with both students and their educators' experiences. In total, 4,024 participants were involved, all sourced from Kuwaiti educational facilities. The data received was then scrutinized via statistical analysis to identify the most impact of taking up and adjusting to online learning challenges. Fig. 1 shows the theoretical framework adopted for this process $[46,47]$. The framework requires a definition of the system under scrutiny as the first stage (educational facilities in Kuwait) before its remit moves on to concerned parties in the second stage (students and their educators). 


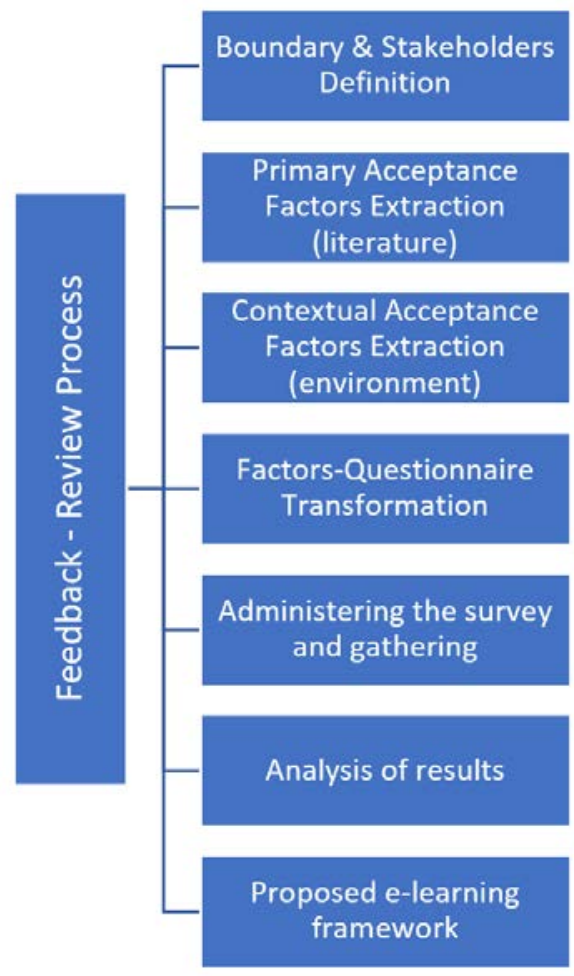

Fig. 1. Theoretical Framework.

The second stage involves utilizing the literature analysis to identify how the challenges of e-learning and its various methods and frameworks are currently being addressed. This assessment highlights the factors needed to analyze the embracing of e-learning. The third stage involves recognizing the contextual issues both teachers and learners face when adjusting to online methods - i.e., the complications of reallife situations. As far as this study is concerned, these contextual issues are gathered from within Kuwait. Once these stages are complete, the factors identified are organized into a table that incorporates the relevant research literature. The fourth stage utilizes the accrued information to form an applicable questionnaire before the survey participants are approached to gather the fifth stage data. An examination of statistical data and recommendations is made in stage six before firm solutions, and frameworks are proposed in stage seven. In support of this work, feedback and review procedures were also in place.

\section{CASE STUdy: EMBRACING ONLINE EDUCATION IN KUWAIT}

Reacting to the complications of lockdown and lack of face-to-face teaching, educational providers throughout Kuwait have been debating methods for proceeding with learning objectives, mainly in terms of how online technology can be utilized. All educational facilities were closed due to the pandemic, leading to a wide range of issues and challenges for those at crucial learning and development stages. The survey study explored here is a result of the various dynamics that emerged.

\section{A. Study Sample}

The focus is on educators and learners registered with Kuwaiti facilities (from both private and public sectors). Sample responses were gathered within two time periods: first, during a period of pilot study, then as part of the resulting primary survey. Once complete, 4,024 participants had returned their responses, with the demographics incorporated into Table I.

TABLE I. SAMPLE FEATURES

\begin{tabular}{|l|l|l|l|}
\cline { 3 - 4 } \multicolumn{2}{c|}{} & Frequency (n) & Percent (\%) \\
\hline \multirow{3}{*}{ Gender } & Male & 864 & 21.5 \\
\cline { 2 - 4 } & Female & 3,160 & 78.5 \\
\hline \multirow{2}{*}{ Institution type } & Student & 2,902 & 72.1 \\
\cline { 2 - 4 } & Instructor & 1,122 & 27.9 \\
\cline { 2 - 4 } & Public & 2,980 & 74.1 \\
\cline { 2 - 4 } & Private & 1,044 & 25.9 \\
\hline
\end{tabular}

B. Instrument for Data Collection

The data collection instrument was purpose-designed to suit key issues identified via the research literature [48, 49, 50, 51]. Furthermore, internal issues became apparent in Kuwait's contexture and incorporated [12, 52, 10]. In total, the questionnaire was made up of 13 questions and split into two parts - part one to obtain the demographic features; part two includes ten key questions that could be subjected to a threepoint Likert-type scale ( 1 for disagree, 2 for neutral, and 3 for agree). Once set up, the questionnaire was sent out to contributors via a number of avenues, including email, social media, and e-messaging. A pilot study was carried out so that any issues with the survey questions could be addressed, which resulted in a Cronbach's Alpha score of 0.901, showing that the questions were applicable and could be moved on into the preliminary study stage. However, the pilot study results are included in the overall total, with all results subjected to frequency, percentage, mean, and standard deviation (SD).

\section{Results}

The preliminary analysis findings are shown in Table II. These results indicate a mean value of 2.10 for item 1 , showing that participants were slightly in favor of e-learning. The question of whether e-learning versatility allows respondents to feel confident turned out to be positive recording a 2.27 mean value. In contrast, an item 3 mean value of 2.35 showed that both learners and educators feel favorable toward online learning for courses of a theoretical context. However, moving on to item 4 shows that this positivity is not reciprocated for learning that depends on laboratory activities - recording a 1.95 mean value. In consideration of synchronous and asynchronous learning objectives, in item 5, synchronous learning received a lower mean value of 2.19 (for the benefits of real-time video conferencing) instead of 2.35 for item 6 . These latter two responses show that users prefer the flexibility of learning as and when they see fit instead of having rigorous calendar activities. 
TABLE II. LEARNERS’ AND EDUCATORS’ VIEWS OF ONLINE LEARNING IN RESPONSE TO LOCKDOWN IN KUWAIT

\begin{tabular}{|c|c|c|c|c|c|c|c|c|c|}
\hline \multirow[b]{2}{*}{ No. } & \multirow[b]{2}{*}{ Questions } & \multicolumn{2}{|c|}{ Disagree } & \multicolumn{2}{|c|}{ Neutral } & \multicolumn{2}{|l|}{ Agree } & \multirow{2}{*}{ Mean } & \multirow{2}{*}{ SD } \\
\hline & & Freq. & $\%$ & Freq. & $\%$ & Freq. & $\%$ & & \\
\hline 1 & $\begin{array}{l}\text { Utilizing e-learning is an applicable approach to continuing with studies } \\
\text { during lockdown. }\end{array}$ & 1,175 & 29.2 & 1,267 & 31.5 & 1,582 & 39.3 & 2.10 & 0.822 \\
\hline 2 & $\begin{array}{l}\text { Having access to e-learning means more versatile approaches, allowing } \\
\text { students to learn according to the time and place they see fit. }\end{array}$ & 1,010 & 25.1 & 928 & 23.1 & 2,086 & 51.8 & 2.27 & 0.835 \\
\hline 3 & E-learning is ideal for theoretical courses. & 748 & 18.6 & 1,134 & 28.2 & 2,142 & 53.2 & 2.35 & 0.774 \\
\hline 4 & E-learning can replace laboratory sessions as an effective alternative. & 1,343 & 33.4 & 1,548 & 38.5 & 1,133 & 28.2 & 1.95 & 0.783 \\
\hline 5 & $\begin{array}{l}\text { I favor live video chat (synchronous) with both the instructor and other } \\
\text { students. }\end{array}$ & 1,233 & 30.6 & 788 & 19.6 & 2,003 & 49.8 & 2.19 & 0.876 \\
\hline 6 & $\begin{array}{l}\text { I favor analyzing resources and study materials (asynchronous) provided by } \\
\text { educators via online platforms (like YouTube). }\end{array}$ & 867 & 21.5 & 873 & 21.7 & 2,284 & 56.8 & 2.35 & 0.812 \\
\hline 7 & $\begin{array}{l}\text { Effective e-learning means that educators and students need to be trained in its } \\
\text { application. }\end{array}$ & 341 & 8.5 & 715 & 17.8 & 2,968 & 73.8 & 2.65 & 0.629 \\
\hline 8 & My facility offers adequate training courses for e-learning. & 2,063 & 51.3 & 990 & 24.6 & 971 & 24.1 & 1.73 & 0.825 \\
\hline 9 & $\begin{array}{l}\text { Our infrastructure (hardware, software, networks) is suitable for the } \\
\text { challenges of e-learning. }\end{array}$ & 1,268 & 31.5 & 1,183 & 29.4 & 1,573 & 39.1 & 2.08 & 0.837 \\
\hline 10 & A range of digital e-learning resources meet the challenges of our curriculum. & 1,446 & 35.9 & 1,465 & 36.4 & 1,113 & 27.7 & 1.92 & 0.793 \\
\hline
\end{tabular}

As item 7 shows, educators and learners both feel that a certain amount of training is essential so they can make the most of e-learning potential (mean 2.65). The feedback indicates that both parties are keen to enhance their understanding of e-learning tools and their capabilities. Compare this to the item 8 result (recording only a 1.73 mean value), and we can conclude that educational facilities are not doing enough of this. Equally as revealing is the 2.08 mean value score for item 9 , which shows an agreement with the notion that the current infrastructure is falling short. Additionally, a 1.92 mean value for item 10 indicates that users are not particularly confident in those remote learning applications that are currently being utilized.

The decision to continue the rest of the academic year with online learning sparked concerns and debate between supporters and skeptics. In response, Kuwait's former education minister claimed that e-learning is a preferable solution to having no access at all. In contrast, Kuwait's previous higher education minister criticized the issues related to e-learning rollout, considering that the country has all the infrastructure needed to make this work [53]. This view led to 11 Kuwait University professors signing their agreement that online learning should be utilized for the remainder of the academic year, calling for 'continuity' as the most crucial factor in someone's education [12]. However, there were some opinions to the contrary, with one professional vocal calling to acknowledge that current e-learning capabilities do not meet the curriculum objectives. He focused on ways in which the present capabilities are falling short, both from educators' and learners' perspectives, as well as the accessibility of specific online resources [10]. Concurring, the Kuwaiti Cultural Office's previous head in Washington DC pointed out the many obstacles to effective learning in an online environment. Part of his concerns included how ready both educators and learners are in respect of utilizing a wide range of innovative but unfamiliar resources and an inability to follow and analyze student progress (Academia 2020). Some of these concerns have been echoed by other academic voices within Kuwait, particularly in the context of readiness [12]. Although facilities worldwide have had no choice but to take this step, that does not mean that the pitfalls should be overlooked. An absence of firm strategies, digital learning resources, and individual readiness are all issues when making such a transformation [54, 7].

\section{INTEGRATED IMPLEMENTATION FRAMEWORK}

The effective deployment of e-learning resources requires numerous crucial attributes to be in sync, including overall management, technical expertise, and social and cultural dynamics. As a result, the following section looks to weigh up these various issues so that the pathways both educators and learners take can be robust and successful throughout society.

Taking direction from the literature review findings - both the successes and pitfalls encountered - and combined with the questionnaire findings, an effective and integrated implementation process is proposed so that all teaching methods and resources can be merged to result in a productive online learning solution. As online capabilities are so crucial, there is a focus on ensuring that professionals develop these solutions in order to safeguard from any usability issues. Nevertheless, the effectiveness of the proposals depends on a range of issues, including the actions taken by the educational facility itself, the overcoming of technical issues like bandwidth, network security, and productivity, as well as links with the centralized Arabic local and regional data center. An infrastructure that is capable of high performance, therefore, is vital to e-learning success. Consequently, the framework put forward incorporates both local infrastructure and cloud-based architecture. So, the results might rely on either public or private cloud models or a merger of the two depending on the most applicable. Besides, all learners need their applicable mobile device in order to access the necessary resources 
irrespective of their location. Should a network be troubled by sluggish performance, this will be inadequate for addressing the teaching and learning challenges involved. Indeed, these issues need to be prioritized within the framework solutions rather than seeking to address them as subsequent performance problems.

As set out in Fig. 2, the e-learning infrastructure advised has been established according to practical issues and contexts particular to Kuwait's challenges, so incorporating both social and cultural factors. The various implementation stages involved are depicted according to specific tiers, all of which are designed to make up an effective distance and blended learning system (DBLS). A bottom-up approach is organized so that implementation can be effectively organized as follows: infrastructure; learning management system; interactive content repository (e-Content); e-learning delivery; and user gateway (portal). Each level involves precise components and design details to inform developers. Plus, an ongoing focus on quality and effectiveness should be pursued according to the content of user reviews and feedback.

The framework incorporates a field of implementation, ranging from knowledge sharing to user collaborations and including platforms for users to engage and feedback. Also, it can be recognized that the various tier levels stand for the Kuwait learning gateway and performance management unit. This tier's key role, alongside quality assurance aspects, is to monitor and improve pedagogical standards to effectively realize learning goals. Doing so is crucial for making sure that teachers, technical advisors, or any managerial figures can monitor the performance of the various tools and resources involved. Quality Assurance (QA) is one of the most critical factors that focus on continuous improvement at several levels that should be applied for each tier and incorporated with every phase of the learning process to ensure its accuracy and effectiveness. The importance of the quality assurance and academic standards describe the level of achievement that the e-learning process and strategies achieve its broader objectives $[55,56]$.

\section{A. Tier (1): Infrastructure Tier}

The infrastructure tier focuses on realizing quality computing resources that offer excellent user-friendliness thanks to either public cloud access or a hybrid approach. Having a hybrid approach means that features are made available via both public and private cloud resources but have to work together seamlessly. The intention is to produce an innovative and fully integrated infrastructure that does not lag behind in any technological aspects and allows learning forums to be merged and utilized. It should also allow those overseeing the educational facilities to make way for incoming advances regarding cloud computing and new technology. As well as being user-friendly and easily accessed, the infrastructure will offer a high performance that does not hold learning back, with users able to carry out their activities dynamically and interactively while also having excellent file storage. Other key aspects include general usability and automation for utilizing an assortment of storage solutions via a centralized approach. Furthermore, cloud computing needs to be upgraded where new IT features and capabilities emerge. The system remains up to date without involving manual maintenance from staff members within the educational facilities. Lastly, the infrastructure needs to be planned to reduce levels of support and technical costs as much as possible.

\section{B. Tier (2): e-Learning Delivery}

An effective distance-learning solution needs to incorporate a wide range of features to offer a robust system, for example, facilitating communication, smart classrooms, and dynamic multimedia resources that are merged with LMS benefits and easily obtainable remotely well as on-site. This eLearning delivery stage requires a range of instructional channels.

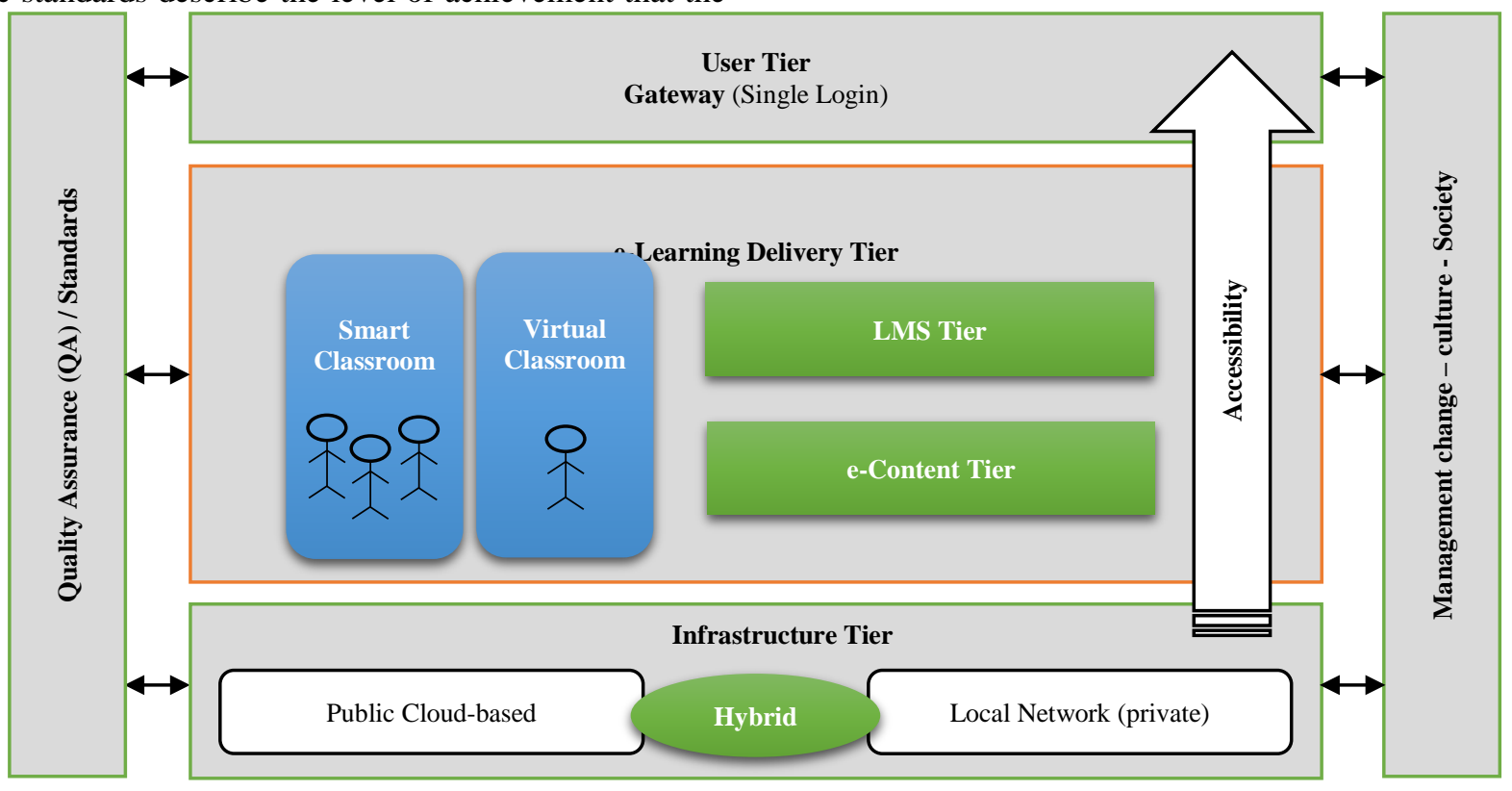

Fig. 2. The Integrated E-Learning Implementation Framework. 
Smart Classroom Component (Blended): Typically, the smart classroom's function is to facilitate merged learning processes in a manner that is unique to each learner, incorporating the latest innovations, and yet present within a traditional classroom environment and overseen by teaching professional. In essence, the smart classroom stands for the upgrade of a conventional classroom environment to merge with modern capabilities. The qualities of recognized teaching methods and innovative technologies are combined, therefore, to the benefit of both learners and teaching professionals.

Virtual Classrooms (Distance): When restrictive scenarios like the Covid-19 lockdown emerge, the benefit of a virtual classroom will be seized upon so that learners and educators can continue to meet and pursue their objectives. This type of learning still occurs in real-time rather than as the student feels fit, with Google, MS Teams, and Moodle all being examples of this approach being taken up successfully worldwide. When functioning to their maximum potential, the virtual classroom will be merged with LMS, as per tier 3 below.

\section{Tier (3): Learning Management System}

This is a crucial tier for realizing potential, though it is sometimes challenging to summarize. Typically, LMS requires a software application to organize the performance, monitoring, and reporting of the educational curriculum [57, 58]. The two tiers of LMS and e-learning delivery combined encompass learning settings that oversee all features, such as course material, content links, student enrollment, and examinations. Educators can monitor how learners perform, which is why there needs to be a focus on both design and integration so that professionals can carry out all their duties while ensuring each student's learning journey is wholly facilitated. Neither location nor time factors should be an issue so long as students have access as and when they please. Simultaneously, educators can make sure all required resources are accessible, and that content is interactive for learning purposes. LMS is central to the system's overall delivery, allowing for course materials to be presented, for students to be monitored, and for performance to be assessed. Plus, a range of different assessment options is incorporated, overcoming one of the key issue's educators face during the lockdown. Therefore, a focus on outcomes and content can remain with LMS acting in place of traditional forms of scrutiny.

\section{Tier (4): Interactive e-Content}

Among the most crucial aspects of an online learning system, interactive e-Content deserves to be analyzed. Effective design and delivery of educational programs are impossible without effective pedagogical integration, alongside access regardless of location or time of day.

This fourth-tier links those critical elements of tiers 3 and 5, positioned between the process of learning and its outcomes. While possible to overlook, interactive e-Content is essential for any robust e-learning solution because, without sound design and technical development, neither the learning process nor its outcomes can run efficiently. Those working on its development need to be familiar with the creation of Learning Objects (LOs), which might be an obscure scientific term to many but account for a number of vital interactive elements, including images and audio. Skilled developers will recognize each LO (or SCO [Sharable Content Object]) as containing several key factors:

- Pedagogical aspects are applicable to the learning object.

- Concepts clarified and delivered via multimedia-based approaches.

- Actions and activities linked with the curriculum's key learning goals.

- The ability to examine how students are interacting with the materials and resources.

The accessibility of the digital e-Content range is vital. Linking students with the heart of the curriculum (as per tier 3), ensuring that no insurmountable obstacles stand between their ability to achieve the best possible results, effectively overcoming challenges such as those posed by lockdown thanks to the versatility of distance learning. Educators can keep up to date with how their students are progressing thanks to LMS's insights, which, if utilized effectively, will inform their teaching practice and allow for final examinations (as per tier 5). In establishing effective e-Content, developers are advised to focus on five key aspects: Analysis, Design, Development, Application, and Evaluation - or the ADDIE [59]. A firm analysis process is advised to ensure that the eContent applied performs according to the specific objectives. This paper's development model is organized according to a 2010 research [17], primarily due to its focus on cultural dynamics. Fig. 3 illustrates the e-Content development model describing the efficient steps requires to develop electronic content based on software engineering practices, including instructional design strategies.

\section{E. Tier (5): User (Portal)}

The learning gateway (user tier) concerns the convenience of access that each user (learner or instructor) enjoys - which any system developer will also experience. Effectively, the gateway functions as a top-level view, allowing a single signin portal and numerous resources applicable to the learning or teaching processes. The key aspects of a learning gateway incorporate the capacity to oversee e-learning systems. The objectives are to contain and present interactive digital eContent, to link administrative and educational materials, to allow for correspondence between the various system users, and to effectively represent all parties in a manner that suits them [60]. Whether a professional is active in a teaching capacity, as a supervisor, manager, or indeed as an overseeing policymaker, an effective system will facilitate their activities, which will have a knock-on positive contribution concerning how professionals communicate and make decisions. This tier is also vital for establishing those tools which allow professionals to assess progress, for example, via generated performance reports. Plus, this tier tends to include a centralized dashboard that adheres to the Business Intelligence (BI) tool, which allows all professionals involved to analyze any performance reports that might enhance or inform their methods. 


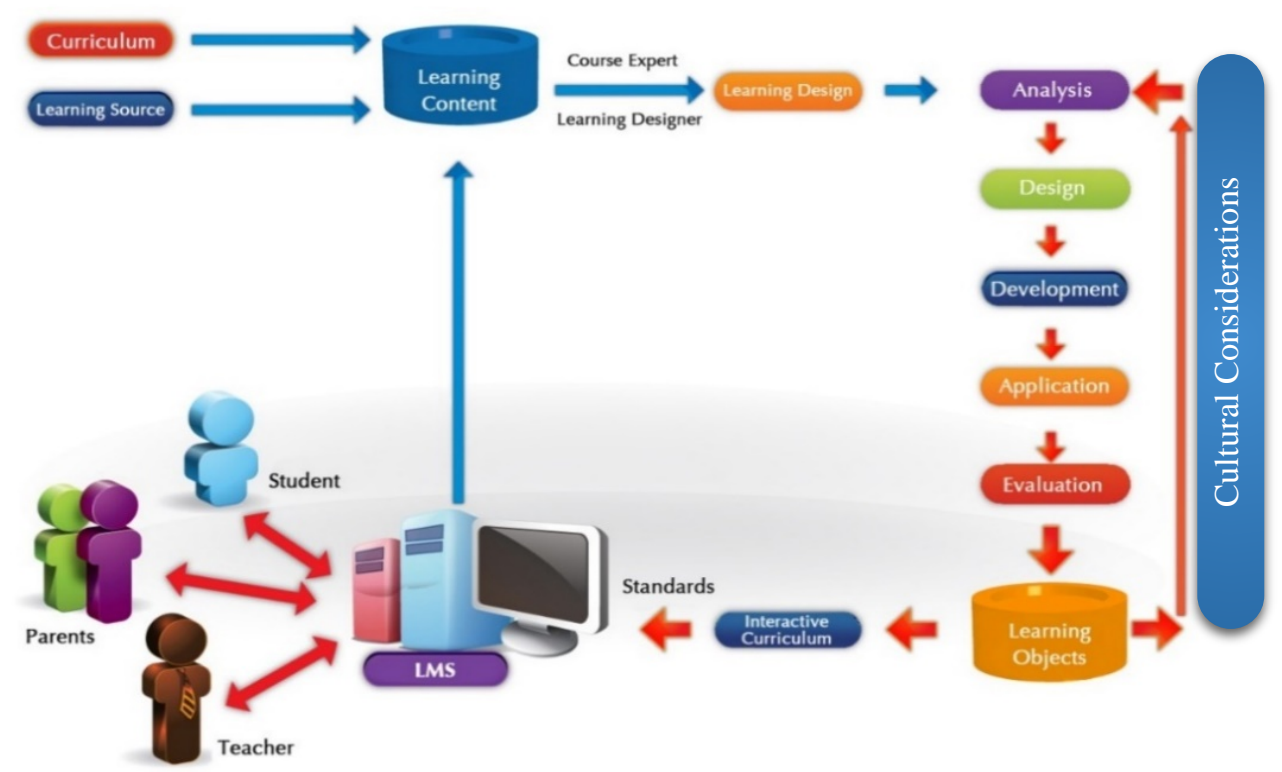

Fig. 3. e-Content Development Model [17].

\section{CONCLUSION AND FUTURE DIRECTION}

This research proposes an integrated framework for elearning implementation that can support a complete or hybrid transformation from traditional teaching methods to online and remote learning. Analysis procedures were chosen to assess the present lockdown situation and the pitfalls and successes that other systems have trialed and recorded. This investigation has also assessed and examined the remote and e-learning structures embraced worldwide and gathered data via a questionnaire. This helped in drawing all the results together to inform a robust implementation framework that, if utilized, can guide Kuwaiti education providers - as with those of neighboring countries - forward in making the most of integrated e-learning. The proposed framework is designed to establish the groundwork that can result in a subsequent dynamic e-learning system in action and aligned with relevant social and cultural contexts. To be efficacious, developers are advised to base their work around e-Content versatility, which should provide the elasticity to connect to the various aspects of e-learning. All possible models and structures can if executed effectively, allow Kuwaiti education providers to make the most of online learning potential without having to worry about the restrictions of lockdown harming professional methods or student progress.

Vital features that impact e-learning uptake as an answer to face-to-face teaching being banned in Kuwait due to pandemic have been analyzed and explored in this paper. The approach has been quantitative in nature, making the most of a large group of respondents gathered from a range of Kuwaiti education facilities. In judging the results, we can reach the firm conclusion that the majority are in favor of digitized learning potential, largely seeing its impact as positive and being keen to overcome any obstacles. However, this does not mean that familiarity with e-learning materials and related technology cannot be upgraded. This study confirms certain issues that prevent some from wholly embracing e-learning, with institutional and individual issues alongside technological factors. Of the latter, the most essential advances need to occur within LMS, infrastructure, online assistance, communication and correspondence tools, and network bandwidth.

Furthermore, within institutions themselves, professionals need to address overall educational strategies to be integrated with online methods and ensure that effective supervision and managerial support are present, along with training initiatives if necessary. The pandemic, although frustrating, is also the best time to get this right, offering an ideal window for assessing all aspects of the online learning experience and refining them for future generations. Therefore, policymakers in Kuwait should prioritize encouraging the design, development, and implementation of innovative new platforms so all these vital lessons can be learned sooner rather than later, if not before the pandemic is over [61]. Other lessons must include being ready for crisis and recognizing that we have no idea when the next lockdown situation will arrive.

Looking ahead to future research, it would be useful if a similar approach was taken but incorporating other GCC countries, for example, the UAE, Saudi Arabia, Qatar, or Bahrain. Comparatively speaking, these countries likely face similar social and cultural challenges, meaning that researchers could work together across countries to upgrade their methods. Plus, adjusting students' approaches is among the key aims of effective e-learning programs, so there could be a closer focus on how students behave regarding new technology and teachers and other contributing professionals. Investigations that focus on analyzing behavior habits may inform developers how users will respond to future developments in class environments and personal studies. Furthermore, we would advise on assessing e-learning systems and how users are making the most of them. A continued focus on performance issues means further upgrades and remaining up to date with modern potential. 


\section{ACKNOWLEDGMENTS}

The current research was funded by the Kuwait Foundation for the Advancement of Sciences under project code: “CORONA PROP 95”.

\section{REFERENCES}

[1] S. Al-Sharhan and A. Al-Hunaiyyan, "Towards an effective integrated elearning system: Implementation, quality assurance and competency models. In Digital information management (icdim)," in Seventh International Conference, Macau, 2012.

[2] P. Serdyukov, "Innovation in education: what works, what doesn't, and what to do about it?," Journal of Research in Innovative Teaching \& Learning, Vol. 10 No. 1, pp. 4-33, 2017.

[3] R. Florida, "Mapping the World's Knowledge Hubs, CityLab," 26 Jan $2017 . \quad$ [Online]. Available: http://www.citylab.com/work/2017/01/mapping-the-worlds-knowledgehubs/505748/?utm_source=feed. [Accessed 3 Feb 2021].

[4] OECD, Innovating Education and Educating for Innovation: The Power of Digital Technologies and Skills, Paris: OECD Publishing, http://dx.doi.org/10.1787/9789264265097-en, 2016.

[5] IGI Global, "IGI Global," 2021. [Online]. Available: https://www.igiglobal.com/dictionary/in-the-pursuit-of-happiness/11494. [Accessed 2021].

[6] C. B. Mpungose, "Emergent transition from face-to-face to online learning in a South African University in the context of the Coronavirus pandemic," Humanit Soc Sci Commun 7, 113. https://doi.org/10.1057/s41599-020-00603-x, 2020.

[7] R. e. a. Baticulon, "Barriers to online learning in the time of COVID-19: A national survey of medical students in the Philippines," 2020. [Online]. Available: https://www.medrxiv.org/content/10.1101/2020.07.16.20155747v2.

[8] A. Al-Hunaiyyan, R. Alhajri, A. Alzayed and B. Alraqqas, "Towards an Effective Distance Learning Model: Implementation Framework for Arab Universities," International Journal of Computer Application. Volume 6, Issue 5, September-October 2016, 2016.

[9] M. AlKharang, Factors that Influence the Adoption of e-Learning An Empirical Study in Kuwait. Phd. Thesis, London: Brunel University London, 2014.

[10] Academia, "Discussion Forum: Online learning in Light of COVID-19," 29 March 2020. [Online]. Available: http://dlvr.it/RSnh0X.

[11] S. Al-Sharhan, A. Al-Hunaiyyan and H. Al-Sharrah, "A new efficient blended e-learning model and framework for k12 and higher education: Design and," in 2010 fifth international conference, 2010.

[12] Al-Anbaa, "Opinions of Faculty Members of Online Learning as a reponse to COVID-19 Crises," 10 April 2020. [Online]. Available: https://alanba.com.kw/961334/?utm_source=whatsapp.

[13] K. Albasayna, Factors Influencing the Use of E-Learning in Schools in Crises Areas: Syrian Teachers' Perspectives, Tallinn University of Technology, Estonia, 2016.

[14] G. Kituyi and I. Tusubira, "A framework for the integration of elearning in higher education institutions in developing countries," International Journal of Education and Development using Information and Communication Technology (IJEDICT), 2013, Vol. 9, Issue 2, pp. 19-36, 2013.

[15] A. Al-Hunaiyyan, R. Alhajri and S. Al-Sharhan, "Perceptions and challenges of mobile learning in Kuwait," Journal of King Saud University - Computer and Information Sciences Volume 30, Issue 2, pp. 279-289, 2018.

[16] H. Beetham and R. Sharpe, Rethinking pedagogy for a digital age: Designing for 21st century learning, 2 ed., London: routledge, 2013.

[17] S. Al-Sharhan, T. Al-Sedrawi and H. Al-Sharrah, E-learning Strategies, and implementation Projects, Ministry of Education, 1 ed., Kuwait: Ministry of Education, 2010.

[18] H. Rodrigues, F. Almeida, V. Figueiredo and S. Lopes, "(2019) Tracking e-learning through published papers: a systematic review.," Comput Education 136, p. 87-98, 2019.
[19] V. Arkorful and N. Abaidoo, "The role of e-learning, advantages and disadvantages of its adoption in higher education," Int J Instruct Technol Distance Learn 12(1), p. 29-42, 2015.

[20] W. Horton, "E-learning by design," John Wiley \& Sons, 2011.

[21] J. Zhang, D. Burgos and S. Dawson, "Advancing open, flexible and distance learning through learning analytics,," Distance Education, 40:3, DOI: 10.1080/01587919.2019.1656151, pp. 303-308, 2019.

[22] C. Nerantzi, "The Use of Peer Instruction and Flipped Learning to Support Flexible Blended Learning During and After the COVID-19 Pandemic.," International Journal of Management and Applied Research. 7. 10.18646/2056.72.20-013, pp. 184-195, 2020.

[23] S. Al-Sharhan, A. Al-Hunaiyan and W. Gueaieb, "Success factors for an efficient blended learning. In Proceedings of the 10th IASTED International Conference on Internet And Multimedia Systems And Applications, pages 77-82," 2006.

[24] A. Ożadowicz, "Modified Blended Learning in Engineering Higher Education during the COVID-19 Lockdown-Building Automation Courses Case Study," Education Sciences 10(10):292. DOI: https://doi.org/10.3390/educsci10100292, 2020.

[25] M. Shahabadia and M. Uplaneb, "Synchronous and asynchronous elearning styles and academic," Procedia - Social and Behavioral Sciences 176, p. 129-138, 2015.

[26] A. Nikoubakht and A. Kiamanesh, "(2019) The comparison of the effectiveness of computer-based education and traditional education on the numerical memory in students with mathematics disorder," J Psychol Sci 18(73), p. 55-65, 2019.

[27] C. Liu and F. Long , "The discussion of traditional teaching and multimedia teaching approach in college English teaching," in International Conference on Management, Education and Social Science (ICMESS), 2014.

[28] A. Bates, Teaching in a digital age: guidelines for designing teaching and learning for a digital age, London: Tony Bates Associates Ltd, 2018.

[29] T. Anderson, "Theories for learning with emerging technologies," Emerging technologies in distance education 7(1), p. 7-23, 2016.

[30] N. Al-Huwail, S. Al-Sharhan and A. Al-Hunaiyyan, "Learning Design for a Successful Blended E-learning Environment: Cultural Dimensions. Journal of Computer Science," INFOCOMP Volume 6 - No. 4, pp. 6069, 2007.

[31] K. Nachimuthu, "Need of e-Content Development on Education," Education Today, An International Journal of Education \& Humanities, ISSN: 2229-5755, Vol. 03., No.02, pp. 72-80, 2012.

[32] B. Czerkawski and E. Lyman, "An Instructional Design Framework for Fostering Student Engagement in Online Learning Environments," TechTrends 60, https://doi.org/10.1007/s11528-016-0110-z, p. 532-539, 2016

[33] B. Lockee, "Shifting digital, shifting context:(re) considering teacher professional development for online and blended learning in the COVID-19 era," Educational Technology Research and Development, 1-4., 2020

[34] S. Al-Sharhan, "Smart classrooms in the context of technologyenhanced learning (TEL) environment: A holistic Approach," in Transforming Education in the Gulf Region - Emerging Learning technologies and Innovative Pedagogy for the 21st Century, London, Taylor \& Francis, 2016.

[35] D. Newton and A. Ellis, "A model for e-learning integration," Honolulu, Hawaii, 2006.

[36] A. Al-Hunaiyyan, A. Al-Sharhan and R. Alhajri, "A New Mobile Learning Model in the Context of the Smart Classrooms Environment: A Holistic Approach," International Journal of Interactive Mobile Technologies (iJIM). Vol.11_No.3(2017), pp. 39-56, 2017.

[37] Y. Hsu and Y. Ching, "A Review of Models and Frameworks for Designing Mobile Learning Experiences and Environments," The Canadian Journal of Learning \& Technology. published by Canadian Center of Science and Education, vol. 41, no. 3, pp. 1-22, 2015.

[38] B. Cheawjindakarn, P. Suwannatthachote and A. Theeraroungchaisri, "Critical Success Factors for Online Distance Learning in Higher Education: A Review of the Literature," in Creative Education 2012, 2012. 
[39] D. O’Doherty, M. Dromey, J. Lougheed and et al. , "Barriers and solutions to online learning in medical education - an integrative review," BMC Medical Education18, $130 \quad$ (2018). https://doi.org/10.1186/s12909-018-1240-0, 2018.

[40] R. Alhajri and A. Al-Hunaiyyan, "Integrating Learning Style in the Design of Educational Interfaces," ACSIJ Advances in Computer Science: an International Journal, Vol. 5, Issue 1, No.19 , January 2016. ISSN : 2322-5157, 2016.

[41] B. Adeoye, "The Era of Digital Technology in Teaching and Learning in Nigeria Educational Institutions. 2020," in The Roles of Technology and Globalization in Educational Transformation, Hershey, PA: IGI Global, 2020, 2020.

[42] R. Alhajri, S. Al-Sharhan, A. Al-Hunaiyyan and T. Alothman, "Design of educational multimedia interfaces: individual differences of learners," in Proceedings of the Second Kuwait Conference on e-Services and eSystems, Kuwait, 2011.

[43] V. Varvel, "Master online teacher competencies," Online Journal of Distance Learning Administration, Spring 2007. Vol.10., No.1, 2007.

[44] S. Dasari, "Using Instructional Design in Developing Instructional New Media Materials," in Proceedings of national seminar on e-learning and its technologies, ELETECH INDIA 2001, Session 4-4, Paper 16, 2001.

[45] J. Lee and S. Jang, "A methodological framework for instructionaldesign model development: Critical dimensions and synthesizedprocedures," Education Technology Research and Development,62(6), doi:10.1007/s11423-014-9352-7, p. 743-765, 2014.

[46] A. Elias and R. Cavana, "Stakeholder Analysis for Systems Thinking and Modelling," $2011 . \quad$ [Online]. Available: https://www.researchgate.net/publication/253711729.

[47] S. Raza, A. Siddiqui and C. Standing, "Exploring Systemic Problems in IS Adoption Using Critical Systems Heuristics," Systemic Practice and Action Research, 32. https://doi.org/10.1007/s11213-018-9467-6, p. 125-153, 2018.

[48] J. Demuyakor, "Coronavirus (COVID-19) and Online Learning in Higher Institutions of Education: A Survey of the Perceptions of Ghanaian International Students in China," Online Journal of Communication and Media Technologies, 10(3), 2020.

[49] A. Chi, Development of the readiness to teach online scale, University of Denver, 2015.

[50] M. Girik Allo, "Is the online learning good in the midst of Covid-19 Pandemic? The case of EFL learners. 10," Jurnal Sinestesia, Vol. 10, No. 1, April 2020, pp. 1-10, 2020.
[51] M. Acosta, A. Sisley, J. Ross, I. Brailsford and A. Bhargav, "Student acceptance of e-learning methods in the laboratory class in Optometry," PLOS ONE 13 (12), 2018.

[52] Anbaa, "Benefits of Distance Learning," 1 April 2020. [Online]. Available: https://alanba.com.kw/959659/?utm_source=whatsapp.

[53] Alanbaa, "Benefits of Distance Learning," 3 May 2020. [Online]. Available: https://alanba.com.kw/959659/?utm_source=whatsapp. [Accessed 3 May 2020].

[54] M. Bączek, M. Zagańczyk-Bączek, M. Szpringer, A. Jaroszyński and B. Wożakowska-Kapłon, "Students' perception of online learning during the COVID-19 pandemic: a survey study of Polish medical students," 2020. [Online]. Available: https://www.researchsquare.com/article/rs41178/v1.

[55] J. Biggs, "The reflective institution: Assuring and enhancing the quality of teaching and learning," Higher Education, 41(3), p. 221-238, 2001.

[56] A. Al-Hunaiyyan, S. Al-Sharhan and H. Al-Sharrah, "A New Instructional Competency Model: Towards an Effective E-Learning System and Environment," International Journal of Information Technology \& Computer Science (IJITCS), vol. 5, pp. 94-103, 2012.

[57] S. Al-Sharhan, A. Al-Hunaiyyan, R. Alhajri and N. Al-Huwail, "Utilization of Learning Management System (LMS) Among Instructors and Students," in Advances in Electronics Engineering. Lecture Notes in Electrical Engineering, vol 619, Singapore , Springer, 2020, pp. 15-23.

[58] A. Al-Hunaiyyan, S. Al-Sharhan and R. Al-Hajri, "Prospects and Challenges of Learning Management Systems in Higher Education," International Journal of Advanced Computer Science and Applications (IJACSA), Vol. $11, \quad$ No. http://dx.doi.org/10.14569/IJACSA.2020.0111209, pp. 73-79, 2020.

[59] K. Shelton and G. Saltsman, "Using the Addie model for teaching online," International Journal of Information And Communication Technology Education, 2(3), pp. 14-26, 2006.

[60] U. Maldonado, G. Khan, J. Moon and J. Rho, "E-learning motivation and educational portal acceptance in developing countries," Online Information Review. 35, pp. 66-85, 2011.

[61] A. Al-Hunaiyyan and S. Al-Sharhan, "The Design of Multimedia elearning Systems: Cultural Considerations.," in Proceeding of the 3rd International Conference on Singals, Circuits and Systems, November 68, 2009, Djerba, Tunisia, 2009. 